\title{
An In-Silico Study of Stable and Environment-Friendly Oryza sativa Urease
}

\author{
Vinod Kumar Yata ${ }^{1(\mathbb{D})}$, Dorothy Das ${ }^{2(\mathbb{D})}$, Ankita Deb ${ }^{2(\mathbb{D})}$, Niharika Das ${ }^{2(\mathbb{D})}$, Gariyoshi Mahanta ${ }^{2(\mathbb{D})}$, \\ Bharti Arora $^{3}$ (D), Venkata Satish Kumar Mattaparthi 2,*(D) \\ Animal Biotechnology Centre, National Dairy Research Institute, Karnal-132001, Haryana, India \\ 2 Molecular Modelling and Simulation Laboratory, Department of Molecular Biology and Biotechnology, Tezpur \\ University, Tezpur-784 028, Assam, India \\ 3 Department of Biotechnology, Dr. B.R. Ambedkar National Institute of Technology Jalandhar, Jalandhar 144 011, Punjab, \\ India \\ * Correspondence: mvenkatasatishkumar@gmail.com, venkata@tezu.ernet.in;
}

Scopus Author ID 54962670000

Received: 15.09.2020; Revised: 8.10.2020; Accepted: 9.10.2020; Published: 14.10.2020

\begin{abstract}
Urea is one of the most extensively used fertilizers in agriculture but has a detrimental impact on the environment. One of the strategies to reduce this impact can be engineering modified plants containing urease enzyme with a considerably higher affinity for urea so that the urea applied in the fields can be significantly reduced. In this study, we have selected Oryza sativa Urease and generated stable mutants having a high affinity for urea. We modeled the 3D structure of the enzyme and identified the potential binding sites by analyzing the binding sites of similar proteins, i.e., 48 urea binding proteins. We found that mutation of Arg578 with Cys near the substrate-binding site of Oryza sativa Urease leads to a stable mutant protein that has a higher binding affinity for urea. This study will lead to a generation of environment-friendly, stable, genetically modified rice crop that consumes lesser urea, without compromising with crop productivity.
\end{abstract}

Keywords: Oryza sativa Urease; molecular docking; high urea affinity; molecular modelling; mutation analysis.

(C) 2020 by the authors. This article is an open-access article distributed under the terms and conditions of the Creative Commons Attribution (CC BY) license (https://creativecommons.org/licenses/by/4.0/).

\section{Introduction}

Plants suffice their nutrient requirements due to the presence of Nickel-dependent metalloenzyme- Urease (EC 3.5.1.5), present in various plant species as the housekeeper enzyme, playing a vital role in catalyzing the hydrolysis of urea, converting it to ammonia in the cytosol, which further acts as a substrate for Nitrogen assimilation in plants [1]. With an estimated production of 480.13 million metric tons in 2016-17, indicated by USDA (United States Department of Agriculture), Oryza sativa (Rice) is one of the predominantly grown cereal crops worldwide, crucially depending on urea as the main source of nitrogen fertilizer [2], which is accessible to plants, only after its hydrolysis, mainly by microbial urease, followed by plant ureases $[3,4]$.

Widespread application of urea for paddy growth has a detrimental impact on the ecosystem, due to the high activity of microbial ureases in the soil leading to ammonia volatilization, phytotoxicity, Nitrate accumulation, suspended seed germination [5], leaching, contamination of nearby water bodies, soil acidification, etc. [6,7]. Similar harmful effects of excess of another nutrient- Phosphorous, have been studied, and novel methods have been 
designed to reduce its impact on the environment [8]. The different strategies employed, such as developing hydrophilic polymers for controlled ammonia release [9], experimenting with ground cover rice production system [10], use of membrane encapsulated starch-g-PLLA urea fertilizer [11], designing urease inhibitors [12] have not been completely successful. The reduced soil urease activity should be accompanied by increased plant urease activity. However, not much has been investigated on targeting the ureolytic activity of Oryza sativa urease itself, which could potentially enhance the urea metabolism and uptake by plants, preventing loses due to ammonia volatilization, ultimately reducing the urea dependence quantitatively, thus, limiting its adverse effects [3, 13-20].

In our study, we designed an environment friendly and stable Oryza sativa Urease mutant so as to enhance the enzyme affinity for urea. This can be used to generate genetically modified rice species containing urease that has a high affinity for urea, such that the amount of urea applied in the fields can be significantly reduced. Thus, large scale production of rice crops will not be accompanied by large scale urea applications in the fields, thus, saving the environment from its catastrophic effects.

\section{Materials and Methods}

\subsection{Modeling of protein structure.}

The amino acid sequence of Oryza sativa Urease (Accession ID BAB78715.1), retrieved from the NCBI database, was used to generate a full-length 3D protein structure with the help of I-TASSER server.

\subsection{Binding-site analysis.}

Multiple sequence alignment of 48 urea-binding proteins (retrieved from RCSBResearch Collaboratory for Structural Bioinformatics database) and Oryza sativa urease was done using Clustal Omega [21]. LIGPLOT analysis of urea-binding sites of closely related protein structures was done with the help of PDBsum [22]. Closely related proteins were structurally aligned and further superimposed with Oryza sativa Urease using UCSF Chimera to identify the binding pocket.

\subsection{Generation of mutants.}

UCSF Chimera [23] was used to visualize and select amino acid residues having a cutoff distance of $3.00 \AA$. We then obtained stabilizing amino acids on the mutation sites by CUPSAT server [24]. Chimera [23] was used to select the most probable rotamers of stabilizing amino acids as mutants, and clashes or contacts were removed so as to stabilize any strain remaining after mutation.

\subsection{Docking.}

The 3D structure of urea was obtained from the Chemspider database. Molecular docking of Urea and Oryza sativa urease and its mutants were carried out using the AutoDock software package (version 4.2) [25] as implemented through the graphical user interface AutoDock Tools (ADT 1.5.6). In docking grid box size of 40x40x40 points covering the whole protein structure was built. A grid spacing of $0.375 \AA$ (approximately one-fourth of the length of the carbon-carbon covalent bond) and distances-dependent functions of the dielectric 
constants was used for the calculation of the energetic map. Confirmation runs were generated by using Lamarckian genetic algorithm searches. Default settings were used with an initial population of 50 randomly placed individuals, a maximum number of $2.5 \times 10^{6}$ energy evaluations, and a maximum number of $2.7 \times 10^{4}$ generations. A mutation size of 0.02 and a crossover rate of 0.8 were chosen. The resultant complex structures were then selected based on binding free energy values.

\section{Results and Discussion}

\subsection{Homology modeling.}

The 3-D structure of Oryza sativa Urease was not available in the Protein Databank, so we modeled the structure using its amino acid sequence, which was retrieved from the NCBI database (Accession ID BAB78715.1). The enzyme consists of a single chain of 848 amino acid residues. I-TASSER server provided 5 full-length models of the protein, out of which the structure with a C-score (confidence score) of 2 (predicting the high quality of model) was selected (Figure 1). It consists of $34 \alpha$-helices, 11 of them being extremely short (with 3-4 amino-acid residues). Most of the helices are amphiphilic, interacting with the solvent, while a few are surrounded by loops. The $29 \beta$-strands arrange themselves in $6 \beta$-sheets, 2 buried in the core, while 4 are amphiphilic. The $2 \beta$-turns consist of loops facing the solvent, while $8 \beta$ strands form a barrel, making a hydrophobic pocket.

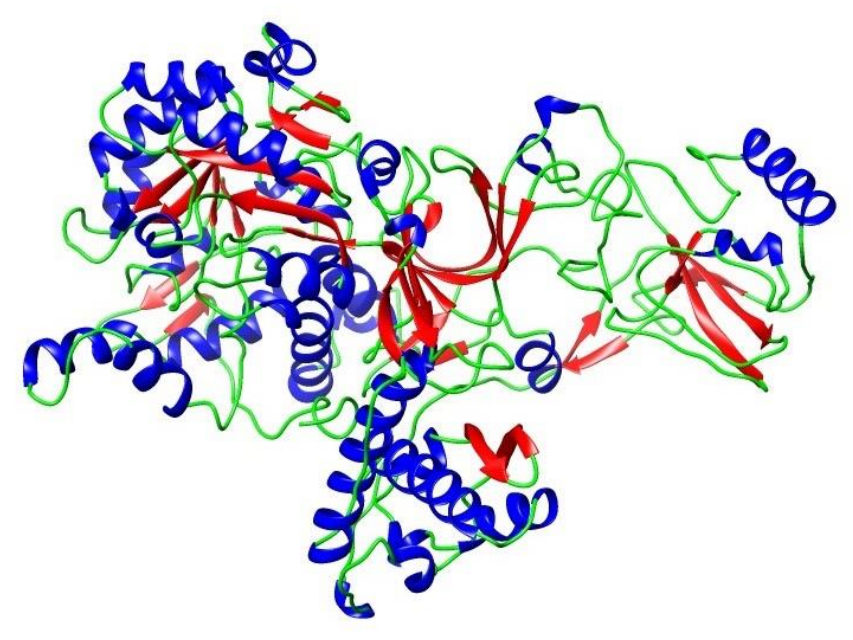

Figure 1. Structure of Oryza sativa Urease modeled by I-TASSER server. Blue color indicates helices, Redbeta-strands, Green-loops.

\subsection{Binding-site analysis.}

In order to perform the binding site analysis, we have first retrieved all the existing Urea binding proteins from the RCSB database. In the RCSB database, we have found 48 such proteins. Multiple sequence alignment of Oryza sativa Urease with the existing 48 urea-binding proteins was carried out. We found that Oryza sativa Urease has high similarity with 4 of the 48 existing urea-binding proteins. Among the 4 proteins, we have chosen Ricin-A from Ricinus communis (PDB id: 2R2X), Moesin from Spodoptera frugiperda (PDB id: 2I1J), Moesin from Spodoptera frugiperda (PDB id: 2I1K) for binding site analysis. We have not considered HLAB*1501 from Homo sapiens (PDB id: 1XR9) for further binding site analysis because of the 
absence of a urea-binding site in the chain C of 1XR9 (which has high similarity with Oryza sativa Urease). We studied the molecular interactions in the Urea-binding sites of the above mentioned 3 proteins with LIGPLOT analysis ( Figure S1). From Figure S1, we can see that the residues Asn6 and Glu73 present in chain A of Moesin (2I1J), as well as $2 \mathrm{I} 1 \mathrm{~K}$, were involved in forming hydrogen bonds with urea in its binding pocket, while the residues Met5, Asn74, Pro75, and Leu76 create a hydrophobic atmosphere around the pocket (Figure S1 a, b) [26]. The urea binding pocket in chain A of Ricin(2R2X) (Supplementary Figure S1 (c)) contains Gly121 and Val81, which form hydrogen bonds with urea, and Ile172, Phe93, Tyr80 make Hydrophobic contacts.[27] ( Table S1).

We structurally aligned Oryza sativa Urease with 2R2X, 2I1J, and 2I1K (Figure 2). From Figure 2c, we can see the residues Gly121 and Phe93 that were present in the urea binding pocket of 2R2X were structurally aligned with the residues Asp622 and Phe580 of Oryza sativa urease, respectively. From Figure 2a, we can see only one of the residue (Asn6) present in the urea binding pocket of 2I1J was structurally aligned with Tyr350 of Oryza sativa Urease. From Figure 2b, we can see none of the residues present in the urea binding pocket of $2 \mathrm{I} 1 \mathrm{~K}$ were involved in structural alignment with the residues in Oryza sativa Urease.

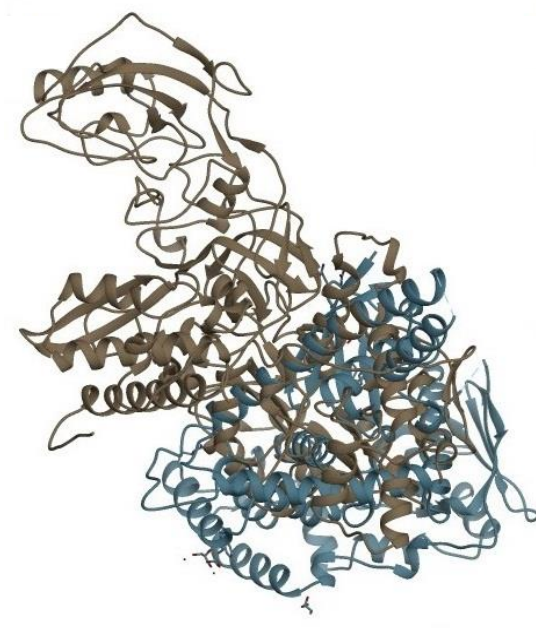

(a)

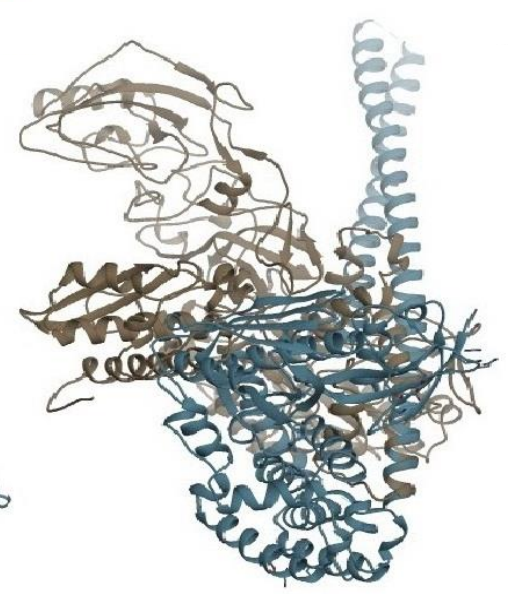

(b)

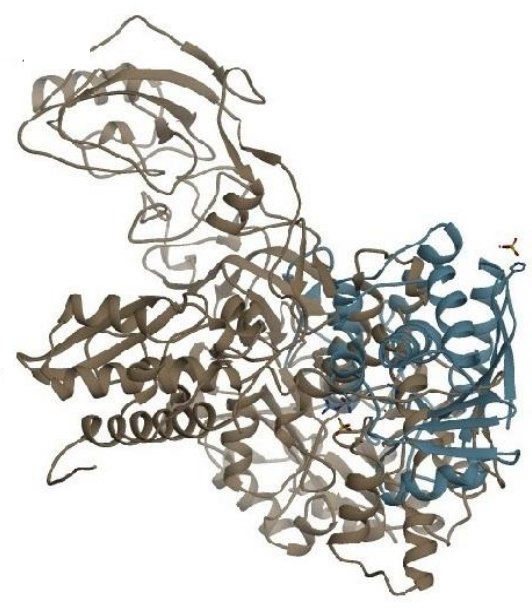

(c)

Figure 2. Structural superimposition of proteins with Oryza sativa Urease (copper) with (a) 2I1J_A (blue) (b) 2I1K_A (blue) (c) 2R2X_A (blue).

Since two residues were aligned in the case of 2R2X structural alignment (Table 1), we chose the corresponding structurally aligned amino acid residues, i.e., Asp622 and Phe580, as the urea binding site for Oryza sativa Urease (Figure 3).

Table 1. Structural alignment of amino acid residues of Oryza sativa urease with other urea bound proteins.

\begin{tabular}{l|l|l|l} 
S.No. & $\begin{array}{l}\text { PDB ID of } \\
\text { Protein }\end{array}$ & $\begin{array}{l}\text { Aligned } \\
\text { Amino Acids }\end{array}$ & Corresponding amino acids of Oryza sativa Urease \\
\hline \multirow{2}{*}{1.} & \multirow{2}{*}{ 2R2X_A } & GLY121 & ASP622 \\
\cline { 3 - 4 } & & VAL81 & Not Aligned \\
\cline { 3 - 4 } & PHE93 & PHE580 \\
\hline \multirow{2}{*}{2.} & \multirow{2}{*}{ 2I1K_A } & ASN6 & Not Aligned \\
\cline { 3 - 4 } & GLU73 & Not Aligned \\
\hline \multirow{2}{*}{3.} & 2I1J_A & ASN6 & TYR350 \\
\cline { 3 - 4 } & & GLU73 & Not Aligned
\end{tabular}




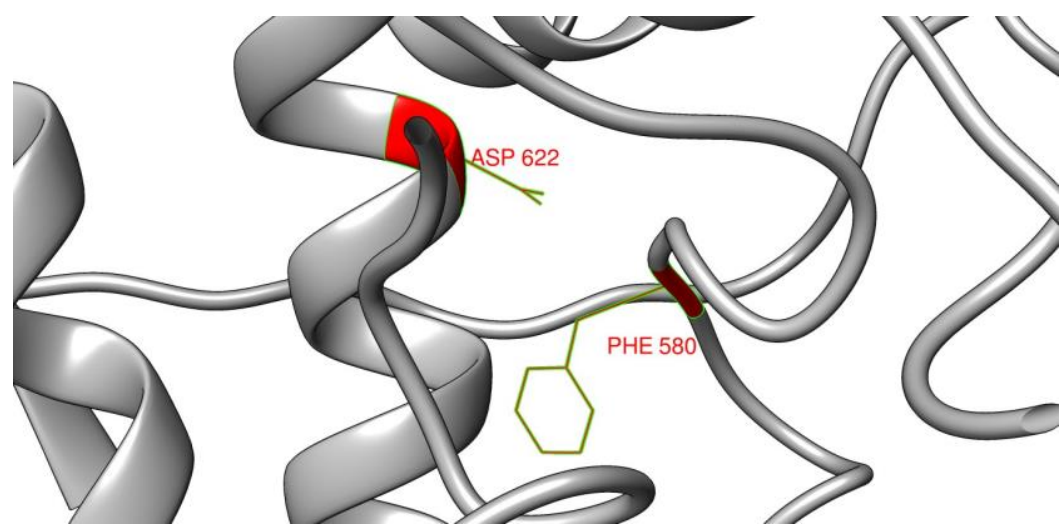

Figure 3. Predicted binding site in the modeled structure of Oryza sativa Urease, showing amino acid residues ASP622 and PHE580 in the binding pocket.

\subsection{Generation of mutants.}

To generate mutants, we initially found the amino acid residues that are present around the predicted substrate-binding pocket. The amino acid residues with a distance less than $3 \AA$ from urea (present in the binding site) were Cys833, Glu621, Arg578, Asp622, and Thr577. The residues forming hydrogen bonds with urea (i.e., Phe580, Asp622) were exempted. All the 4 residues were checked for their possible amino acid replacements with the help of CUPSAT server. Thus, a list of possible stabilizing and destabilizing amino acid residues was found for each of the 4 amino acid point mutations in protein (Table S2). Hence, we obtained 2 single mutants and 2 double mutants- Arg578 was replaced with Cys, to generate OS_R587C, Arg578 replaced with Pro, to form OS_R578P. The double mutants produced were Arg578Val/Cys833Val (OS_R578V/OS_C833V) and Thr577Lys/Glu621Met (OS_T577K /OS_E621M).

Ligand (Urea) - protein (Urease) interactions for the native (originally modeled structure) and different mutants were analyzed by molecular docking to find mutant with the least binding energy, and thus, the highest binding affinity for urea. The native structure of modeled Oryza sativa Urease (OS_native) had binding energy of $-4.47 \mathrm{kcal} / \mathrm{mol}$ and inhibition constant of $527.59 \mu \mathrm{M}$ (Table 2), with Lys656, Ala619, Ile618, Phe580 being the interacting amino acid residues, forming hydrogen bonds with urea (Figure 4).

Table 2. Docking Analysis of Oryza sativa urease with urea.

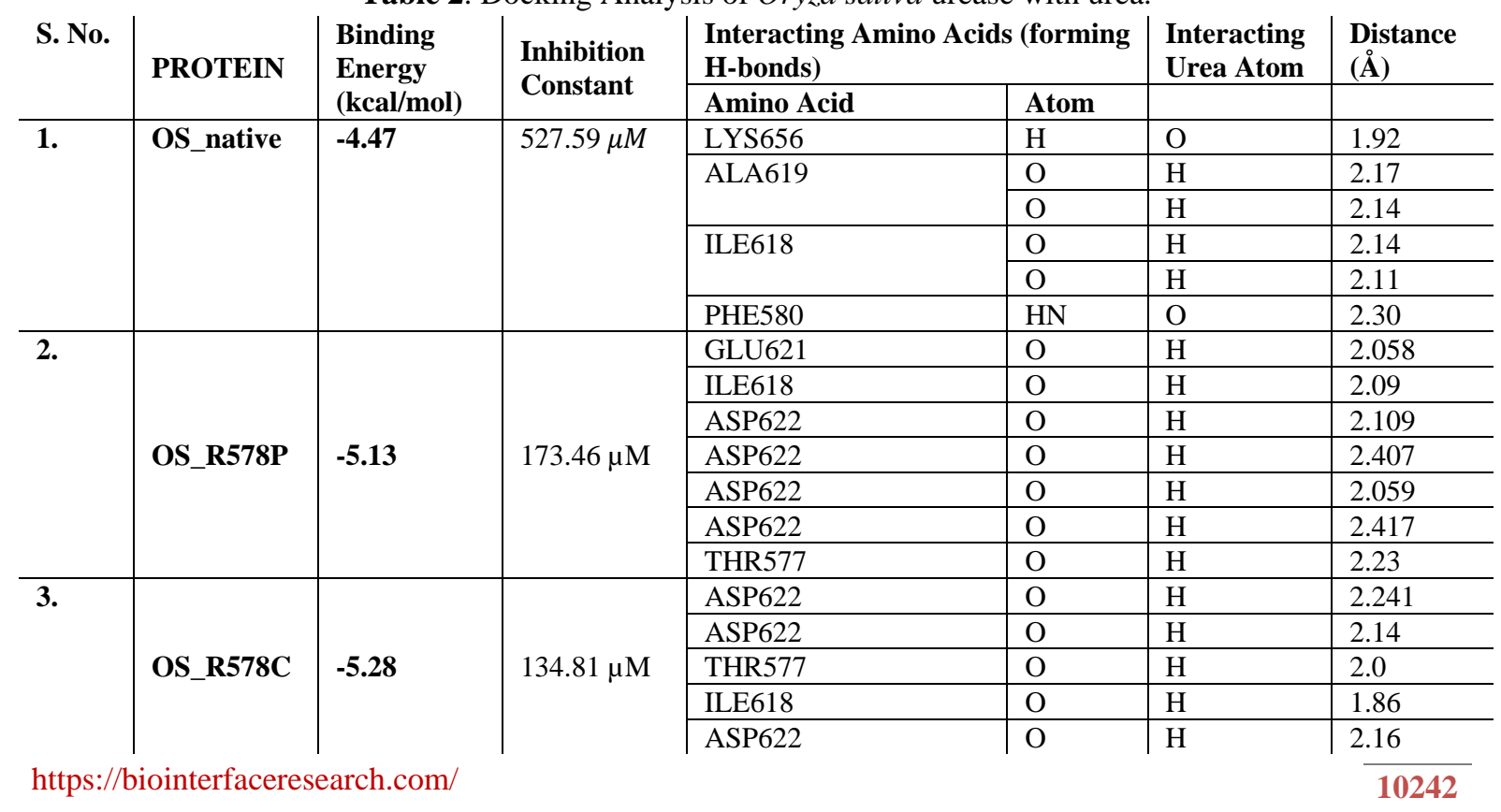




\begin{tabular}{|c|c|c|c|c|c|c|c|}
\hline \multirow[t]{3}{*}{ S. No. } & \multirow[t]{3}{*}{ PROTEIN } & \multirow{3}{*}{$\begin{array}{l}\text { Binding } \\
\text { Energy } \\
\text { (kcal/mol) }\end{array}$} & \multirow{3}{*}{$\begin{array}{l}\text { Inhibition } \\
\text { Constant }\end{array}$} & \multicolumn{2}{|c|}{$\begin{array}{l}\text { Interacting Amino Acids (forming } \\
\text { H-bonds) }\end{array}$} & \multirow[t]{2}{*}{$\begin{array}{l}\text { Interacting } \\
\text { Urea Atom }\end{array}$} & \multirow[t]{2}{*}{$\begin{array}{l}\text { Distance } \\
\text { (̊) }\end{array}$} \\
\hline & & & & Amino Acid & Atom & & \\
\hline & & & & GLU621 & $\mathrm{O}$ & $\mathrm{H}$ & 2.129 \\
\hline \multirow[t]{6}{*}{4.} & \multirow{6}{*}{$\begin{array}{l}\text { OS_R578V } \\
/ \\
\text { OS_C833V }\end{array}$} & \multirow{6}{*}{-5.21} & \multirow{6}{*}{$150.88 \mu \mathrm{M}$} & ASP622 & $\mathrm{O}$ & $\mathrm{H}$ & 2.213 \\
\hline & & & & ASP622 & $\mathrm{O}$ & $\mathrm{H}$ & 2.166 \\
\hline & & & & THR577 & $\mathrm{O}$ & $\mathrm{H}$ & 2.01 \\
\hline & & & & ASP622 & $\mathrm{O}$ & $\mathrm{H}$ & 2.186 \\
\hline & & & & ASP622 & $\mathrm{O}$ & $\mathrm{H}$ & 2.285 \\
\hline & & & & ILE618 & $\mathrm{O}$ & $\mathrm{H}$ & 2.395 \\
\hline \multirow[t]{7}{*}{5.} & \multirow{7}{*}{$\begin{array}{l}\text { OS_T577K } \\
/ \\
\text { OS_E621M }\end{array}$} & \multirow{7}{*}{-4.85} & \multirow{7}{*}{$279.65 \mu \mathrm{M}$} & GLU550 & $\mathrm{HN}$ & $\mathrm{O}$ & 2.132 \\
\hline & & & & GLU550 & $\mathrm{O}$ & $\mathrm{H}$ & 2.0 \\
\hline & & & & LYS577 & $\mathrm{H}$ & $\mathrm{N}$ & 2.04 \\
\hline & & & & GLY551 & $\mathrm{HN}$ & $\mathrm{N}$ & 2.20 \\
\hline & & & & HIS548 & $\mathrm{O}$ & $\mathrm{H}$ & 2.08 \\
\hline & & & & THR574 & $\mathrm{O}$ & $\mathrm{H}$ & 2.278 \\
\hline & & & & THR574 & $\mathrm{O}$ & $\mathrm{H}$ & 2.17 \\
\hline
\end{tabular}

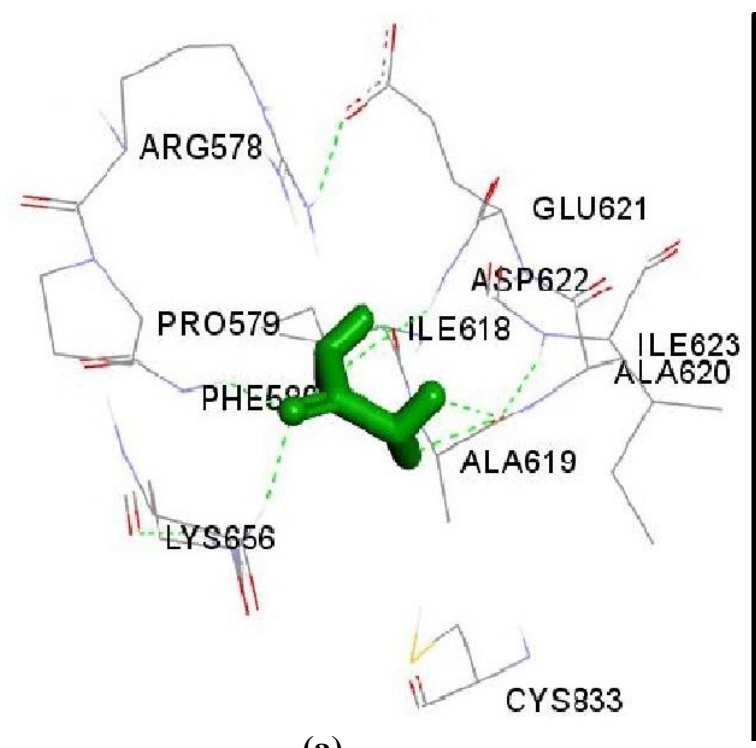

(a)

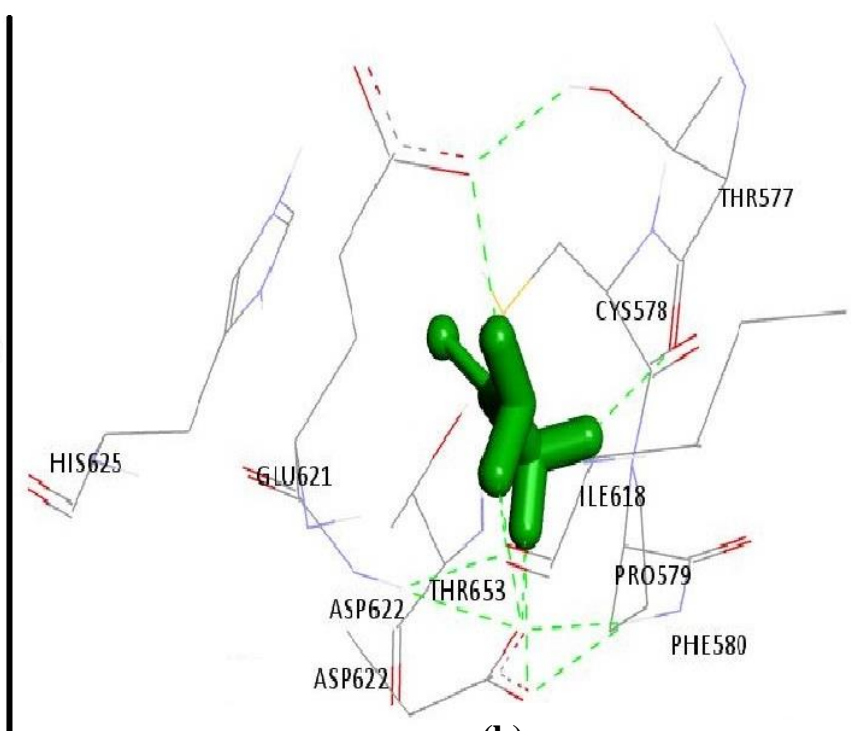

(b)

Figure 4. Computed structures are showing molecular interactions of (a) OS_native with urea and (b) OS_R578C with urea. Green color indicates hydrogen bonding.

Further, Asp622, Thr577, Ile618, Glu621 were the interacting amino acid residues of Arg578Cysmutant of Oryza sativa Urease (OS_R587C), with a binding energy of -5.28 $\mathrm{kcal} / \mathrm{mol}$ and inhibition constant of $134.81 \mu \mathrm{M}$, thus regarded as best binding affinity with urea of the proteins given in Table 1. Arg578Val/Cys833Val (OS_R578V/OS_C833V) and urea gave second best binding affinity with a binding energy of -5.21 , followed by mutant Arg578Pro (OS_R578P) and then mutant Thr577Lys/Glu621Met (OS_T577K /OS_E621M).

There have been many studies to determine urea-urease interactions or urease activity [28-40] of different plant species. The free binding energy of our mutated enzyme $(-5.28$ $\mathrm{kcal} / \mathrm{mol})$ is very less as compared to the energy predicted of Arabidopsis thaliana (-3.28 $\mathrm{kcal} / \mathrm{mol})$, and almost comparable to that of Canavalia ensiformis $(-5.7 \mathrm{kcal} / \mathrm{mol})$ [41]. In the recent past, we can see quite a number of in-silico studies in the literature that have been used to produce various genetically modified crops with novel properties, such as the production of $\beta$-carotene in rice endosperm [42], in-silico designing $\alpha$-gliadin peptidase against celiac disease [43], developing crops that can withstand high abiotic stresses [44], etc. Thus, the computationally designed high urea-affinity enzyme can be used to generate environment 
friendly, genetically modified rice crop which has minimum urea requirement, high Nitrogen Use Efficiency (NUE), without any compromise in its productivity.

\section{Conclusions}

We modeled the structure of Oryza sativa Urease, and it is found to be stable. We identified 2 urea binding sites in the modeled structure by analyzing the binding patterns of amino acids with urea in the 48 urea-binding proteins. We predicted the binding pocket consisting of Phe580 and Asp622 residues, based on high structural similarity and sequence alignment of native protein with Ricin. We created mutants of the modeled structure by replacing the amino acids near the binding site of the protein, with favorable and stabilizing amino acid residues. From the analysis of the mutants, we found OS_R578C (Arg578Cys mutation) to have higher urea binding affinity than the native protein. Furthermore, OS_R578P and double mutant OS_R578V/OS_C833V had similar binding energies, while OS_T577K/OS_E621M had the least binding affinity among the mutants, but still a higher affinity in comparison to the native protein. So, the mutant OS_R578C is stable and has the highest binding affinity for urea. Thus, a high affinity for urea will enhance urea metabolism and uptake by paddy, reducing environmental hazards caused by nitrogen losses from agricultural systems. This can be used as a template to generate an eco-friendly and stable genetically modified cereal crop (rice), which prevents hazards caused by excessive urea consumption in fields.

\section{Funding}

This research received no external funding.

\section{Acknowledgments}

M.V.S.K. would like to thank the Tezpur University and University Grants Commission, India, for the start-up grant and DBT funded Bioinformatics Infrastructure facility in the Department of Molecular Biology and Biotechnology at Tezpur University for providing us computational facility to carry out this research work. V.K.Y. would like to thank the Department of Biotechnology, Government of India, for providing financial support from "DBT-RA Program in Biotechnology \& Life Sciences." He also would like to extend his gratitude to Dr. M. S. Chauhan, Director, ICAR-National Dairy Research Institute (NDRI), Karnal, India, and Dr. A. K. Mohanty, NDRI, for providing lab space.

\section{Conflicts of Interest}

The authors declare no conflict of interest.

\section{References}

1. Polacco, J.C.; Holland, M.A. Roles of urease in plant cells. Int. Rev. Cytol. 1993, 145, 65-103, https://doi.org/10.1016/S0074-7696(08)60425-8.

2. Ishii, S.; Ikeda, S.; Minamisawa, K.; Senoo, K. Nitrogen Cycling in Rice Paddy Environments: Past Achievements and Future Challenges. Microbes Environ. 2011, 26, 282-292, https://doi.org/10.1264/jsme2.ME11293.

3. Witte, C.-P. Urea metabolism in plants. Plant Sci. 2011, 180, 431-438, https://doi.org/10.1016/j.plantsci.2010.11.010.

4. Sharma, N.; Sinha, V.B.; Gupta, N.; Rajpal, S.; Kuchi, S.; Sitaramam, V.; Parsad, R.; Raghuram, N. Phenotyping for Nitrogen Use Efficiency: Rice Genotypes Differ in N-Responsive Germination, Oxygen 
Consumption, Seed Urease Activities, Root Growth, Crop Duration, and Yield at Low N. Front Plant Sci. 2018, 1 , https://doi.org/10.3389/fpls.2018.01452.

5. Bremner, J.M.; Krogmeier, M.J. Evidence that the adverse effect of urea fertilizer on seed germination in soil is due to ammonia formed through hydrolysis of urea by soil urease. Proc Natl Acad Sci U S A. 1989, 86, 8185-8188, https://doi.org/10.1073/pnas.86.21.8185.

6. Ghosh, B.C.; Bhat, R. Environmental hazards of nitrogen loading in wetland rice fields. Environ. Pollut. 1998, 102, 123-126, https://doi.org/10.1016/S0269-7491(98)80024-9.

7. Golding, A.-L.; Dong, Z. Hydrogen production by nitrogenase as a potential crop rotation benefit. Environ. Chem. Lett. 2010, 8, 101-121, https://doi.org/10.1007/s10311-010-0278-y.

8. McDowell, R.W.; Catto, W. Alternative fertilisers and management to decrease incidental phosphorus loss. Environ. Chem. Lett. 2005, 2, 169-174, https://doi.org/10.1007/s10311-005-0099-6.

9. Mikkelsen, R.L. Using hydrophilic polymers to control nutrient release. Fertil Res. 1994, 38, 53-59, https://doi.org/10.1007/bf00750062.

10. Tao, H.; Brueck, H.; Dittert, K.; Kreye, C.; Lin, S.; Sattelmacher, B. Growth and yield formation of rice (Oryza sativa L.) in the water-saving ground cover rice production system (GCRPS). Field Crops Res. 2006, 95, 1-12, https://doi.org/10.1016/j.fcr.2005.01.019.

11. Guo; Liu; Zhan; Wu, L. Preparation and Properties of a Slow-Release Membrane-Encapsulated Urea Fertilizer with Superabsorbent and Moisture Preservation. Ind. Eng. Chem. Res. 2005, 44, 4206-4211, https://doi.org/10.1021/ie0489406.

12. Gioacchini, P.; Nastri, A.; Marzadori, C.; Giovannini, C.; Vittori Antisari, L.; Gessa, C. Influence of urease and nitrification inhibitors on $\mathrm{N}$ losses from soils fertilized with urea. Biol. Fert Soils 2002, 36, 129-135, https://doi.org/10.1007/s00374-002-0521-1.

13. Chen, J.; Arafat, Y.; Ud Din, I.; Yang, B.; Zhou, L.; Wang, J.; Letuma, P.; Wu, H.; Qin, X.; Wu, L.; Lin, S.; Zhang, Z.; Lin, W. Nitrogen Fertilizer Amendment Alter the Bacterial Community Structure in the Rhizosphere of Rice (Oryza sativa L.) and Improve Crop Yield. Front Microbiol. 2019, 10, https://doi.org/10.3389/fmicb.2019.02623.

14. Ren, Z.; Qi, D.; Pugh, N.; Li, K.; Wen, B.; Zhou, R.; Xu, S.; Liu, S.; Jones, A.R. Improvements to the Rice Genome Annotation Through Large-Scale Analysis of RNA-Seq and Proteomics Data Sets. Mol Cell Proteomics 2019, 18, 86-98, https://doi.org/10.1074/mcp.RA118.000832.

15. Apoorva, M.R.; Rao, P.C.; Padmaja, G.; Reddy, R.S. Activity of soil urease,phosphatase and dehydrogenase as influenced by various sources of Zinc in rice(Oryza Sativa L.). Int.J.Curr.Microbiol.App.Sci. 2018, 7, 2640-2647, https://doi.org/10.20546/ijcmas.2018.701.315.

16. Hirooka, Y.; Homma, K.; Shiraiwa, T.; Makino, Y.; Liu, T.-s.; Xu, Z.; Tang, L. Yield and growth characteristics of erect panicle type rice (Oryza sativa L.) cultivar, Shennong265 under various crop management practices in Western Japan. Plant Prod. Sci. 2018, 21, 1-7, https://doi.org/10.1080/1343943X.2018.1426993.

17. Kimbembe, R.E.R.; Li, G.; Fu, G.; Feng, B.; Fu, W.; Tao, L.; Chen, T. Proteomic analysis of salicylic acid regulation of grain filling of two near-isogenic rice (Oryza sativa L.) varieties under soil drying condition. Plant Physiol. Biochem. 2020, 151, 659-672, https://doi.org/10.1016/j.plaphy.2020.04.006.

18. Li, Y.; Pang, H.-D.; He, L.-Y.; Wang, Q.; Sheng, X.-F. Cd immobilization and reduced tissue Cd accumulation of rice (Oryza sativa wuyun-23) in the presence of heavy metal-resistant bacteria. Ecotox Environ Safe 2017, 138, 56-63, https://doi.org/10.1016/j.ecoenv.2016.12.024.

19. Khan, M.; Khan, S.U.; Rehman, A.; Khan, K.; Anjum, M.M.; Ali, N; Shah, K.; Saifullah. Evaluation of various rice (Oryza Sativa L.) genotypes for yield and yield characters under agro ecological conditions of Peshawar. Adv Plants Agric Res. 2018, 8, 491-494, https://doi.org/10.15406/apar.2018.08.00373.

20. Liu, J.; Zhang, J.; Chen, X.; Du, Y.; Li, J.; Sun, H.; Peng, T.; Xin, Z.; Zhao, Q. Effects of N top-dressing modes of panicle fertilization on soil enzymes activity and yield of rice (Oryza sativa L.). J. Agric. Sci. 2019, 157, 109-116, https://doi.org/10.1017/S0021859619000273.

21. Sievers, F.; Wilm, A.; Dineen, D.; Gibson, T.J.; Karplus, K.; Li, W.; Lopez, R.; McWilliam, H.; Remmert, M.; Söding, J.; Thompson, J.D.; Higgins, D.G. Fast, scalable generation of high-quality protein multiple sequence alignments using Clustal Omega. Mol. Syst. Biol. 2011, 7, https://doi.org/10.1038/msb.2011.75.

22. Wallace, A.C.; Laskowski, R.A.; Thornton, J.M. LIGPLOT: a program to generate schematic diagrams of protein-ligand interactions. Protein Eng. Des. Sel. 1995, 8, 127-134, https://doi.org/10.1093/protein/8.2.127.

23. Pettersen, E.F.; Goddard, T.D.; Huang, C.C.; Couch, G.S.; Greenblatt, D.M.; Meng, E.C.; Ferrin, T.E. UCSF Chimera--a visualization system for exploratory research and analysis. J Comput Chem. 2004, 25, 16051612.

24. Parthiban, V.; Gromiha, M.M.; Schomburg, D. CUPSAT: prediction of protein stability upon point mutations. Nucleic Acids Res. 2006, 34, W239-W242, https://doi.org/10.1093/nar/gk1190.

25. Morris, G.M.; Huey, R.; Lindstrom, W.; Sanner, M.F.; Belew, R.K.; Goodsell, D.S.; Olson, A.J. AutoDock4 and AutoDockTools4: Automated docking with selective receptor flexibility. J. Comput. Chem. 2009, 30, 2785-2791. 
26. Li, Q.; Nance, M.R.; Kulikauskas, R.; Nyberg, K.; Fehon, R.; Karplus, P.A.; Bretscher, A.; Tesmer, J.J.G. Self-masking in an Intact ERM-merlin Protein: An Active Role for the Central $\alpha$-Helical Domain. J. Mol. Biol. 2007, 365, 1446-1459, https://doi.org/10.1016/j.jmb.2006.10.075.

27. Carra, J.H.; McHugh, C.A.; Mulligan, S.; Machiesky, L.M.; Soares, A.S.; Millard, C.B. Fragment-based identification of determinants of conformational and spectroscopic change at the ricin active site. BMC Struct Biol. 2007, 7, https://doi.org/10.1186/1472-6807-7-72.

28. Svane, S.; Sigurdarson, J.J.; Finkenwirth, F.; Eitinger, T.; Karring, H. Inhibition of urease activity by different compounds provides insight into the modulation and association of bacterial nickel import and ureolysis. Sci. Rep. 2020, 10, https://doi.org/10.1038/s41598-020-65107-9.

29. Yang, D.; Fan, J.; Cao, F.; Deng, Z.; Pojman, J.A.; Ji, L. Immobilization adjusted clock reaction in the ureaurease-H+ reaction system. RSC Adv. 2019, 9, 3514-3519, https://doi.org/10.1039/C8RA09244C.

30. Zhao, H.; Wu, Y.; Xu, Z.; Ma, R.; Ding, Y.; Bai, X.; Rong, Q.; Zhang, Y.; Li, B.; Ji, X. Mechanistic Insight Into the Interaction Between Helicobacter pylori Urease Subunit $\alpha$ and Its Molecular Chaperone Hsp60. Front Microbiol. 2019, 10, https://doi.org/10.3389/fmicb.2019.00153.

31. Graham, D.Y.; Miftahussurur, M. Helicobacter pylori urease for diagnosis of Helicobacter pylori infection: A mini review. J. Adv. Res.2018, 13, 51-57, https://doi.org/10.1016/j.jare.2018.01.006.

32. Kappaun, K.; Piovesan, A.R.; Carlini, C.R.; Ligabue-Braun, R. Ureases: Historical aspects, catalytic, and non-catalytic properties - A review. J. Adv. Res. 2018, 13, 3-17, https://doi.org/10.1016/j.jare.2018.05.010.

33. Cordero,I.; Snell,S.; Bardgett,R.D. High throughput method for measuring urease activity in soil. Soil Biol Biochem. 2019,134, 72-77, https://doi.org/10.1016/j.soilbio.2019.03.014.

34. Sigurdarson, J. J.; Svane, S.; Karring, H. Development of a M9-based Urea Medium (M9U) for Sensitive and Real-time Monitoring of Ureolytic Activity of Bacteria and Cell-free Urease. MicrobiologyOpen 2020, 9 , https://doi.org/10.1002/mbo3.976.

35. Fu,Q.; Abadie, M.; Carswell,A.; Misselbrook,T.H.; Clark,I.M.; Hirsch, P.R. Effects of urease and nitrification inhibitors on soil N, nitrifier abundance and activity in a sandy loam soil. Biol Fert Soils 2020,56,185-194, https://doi.org/10.1007/s00374-019-01411-5.

36. Feyzi, H.;Chorom, M.; Bagheri, G. Urease activity and microbial biomass of carbon in hydrocarbon contaminated soils. A case study of cheshmeh-khosh oil field, Iran. Ecotox Environ Saf. 2020, 199,110664, https://doi.org/10.1016/j.ecoenv.2020.110664.

37. Kaskheli,M.A.; Wu,L.; Chen,G.; Chen,L.; Hussain,S.; Song,D.; Liu,S.; Feng,G. Isolation and Characterization of Root-Associated Bacterial Endophytes and Their Biocontrol Potential against Major Fungal Phytopathogens of Rice (Oryza sativa L.). Pathogens. 2020, 9,172, https://doi.org/10.3390/pathogens9030172.

38. Budiono, R.; Adinurani,P.G.; Soni,P. Effect of new NPK fertilizer on lowland rice (Oryza sativa L.) growth. Earth and Env Sci, 2019, 293, 012034, https://doi.org/10.1088/1755-1315/293/1/012034.

39. Sircar,S.; Parekh,N. Meta-analysis of drought-tolerant genotypes in Oryza sativa: A network-based approach. Plos one. 2019, 14, e0216068, https://doi.org/10.1371/journal.pone.0216068.

40. Smita,S.; Katiyar, A.; Lenka, S.K.; Dalal, M.; Kumar,A.; Mahtha,S.K.; Yadav,G.; Chinnusamy,V.; Pandey, D.M.; Bansal,K.C. Gene network modules associated with abiotic stress response in tolerant rice genotypes identified by transcriptome meta-analysis. Funct Integr Genomics. 2020, 20, 29-49, https://doi.org/10.1007/s10142-019-00697-w.

41. Yata, V.K.; Thapa, A.; Mattaparthi, V.S.K. Structural insight into the binding interactions of modeled structure of Arabidopsis thaliana urease with urea: an in silico study. J. Biomol. Struct. Dyn. 2015, 33, 845851, https://doi.org/10.1080/07391102.2014.915765.

42. Ye, X.; Al-Babili, S.; Klöti, A.; Zhang, J.; Lucca, P.; Beyer, P.; Potrykus, I. Engineering the Provitamin A ( $\beta$-Carotene) Biosynthetic Pathway into (Carotenoid-Free) Rice Endosperm. Science. 2000, 287, 303-305, https://doi.org/10.1126/science.287.5451.303.

43. Gordon, S.R.; Stanley, E.J.; Wolf, S.; Toland, A.; Wu, S.J.; Hadidi, D.; Mills, J.H.; Baker, D.; Pultz, I.S.; Siegel, J.B. Computational Design of an $\alpha$-Gliadin Peptidase. J. Am. Chem. Soc. 2012, 134, 20513-20520, https://doi.org/10.1021/ja3094795.

44. Varshney, R.K.; Bansal, K.C.; Aggarwal, P.K.; Datta, S.K.; Craufurd, P.Q. Agricultural biotechnology for crop improvement in a variable climate: hope or hype? Trends Plant Sci. 2011, 16, 363-371, https://doi.org/10.1016/j.tplants.2011.03.004.

\section{Supplementary files}


Table S1. Amino acids involved in hydrogen bonding and hydrophobic contacts of closely related proteins with respect to Oryza sativa urease for urea ligand with the help of LIGPLOT (PDBsum).

\begin{tabular}{l|l|l|l} 
PDB ID & Chain & Hydrogen Bonds (with urea) & Hydrophobic contacts (with urea) \\
\hline 2I1J & A & ASN6, GLU73 & MET5, ASN74, PRO75, LEU76 \\
\hline 2I1K & A & ASN6, GLU73 & ASN74, MET5, LEU76 \\
\hline 2R2X & A & GLY121, VAL81 & ILE172, PHE93, TYR80
\end{tabular}

Table S2. List of stabilizing and destabilizing amino acids for the mutation in Oryza sativa Urease using

\begin{tabular}{l|l|l}
\multirow{2}{*}{ Amino Acid } & \multicolumn{2}{c}{ CUPSAT server. } \\
Overall Stability
\end{tabular}

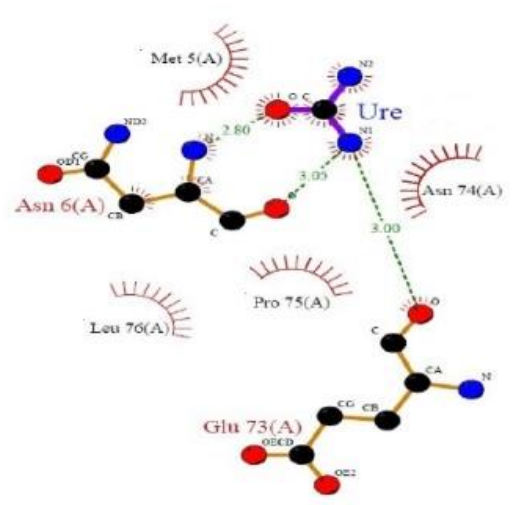

(a)

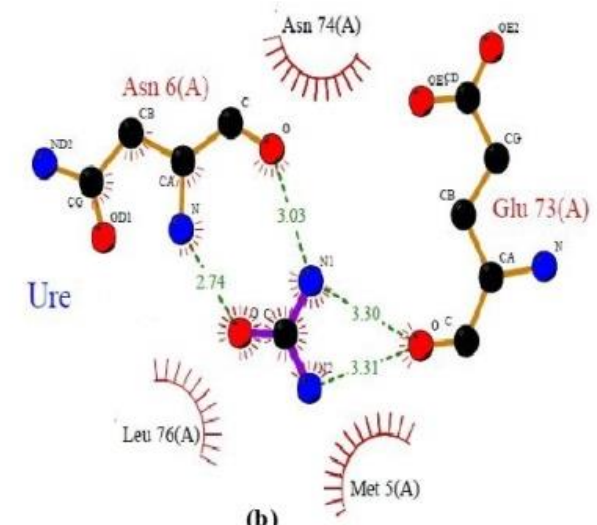

(b)

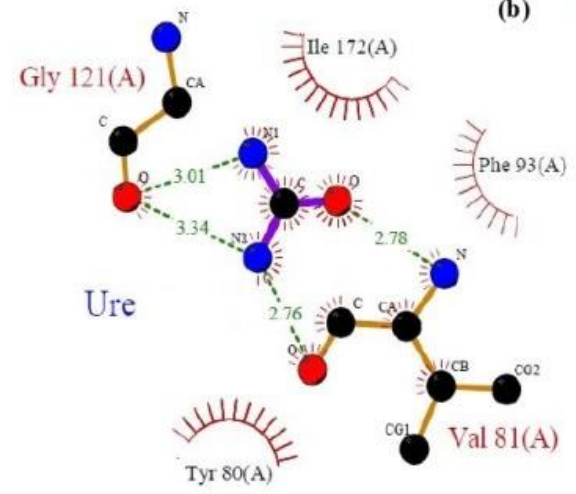

(c)

Figure S1. LIGPLOTs showing the interacting residues of a protein molecule with urea (a) Interaction of urea with chain A of 2I1J, ASN6, GLU76 are forming Hydrogen bond, and MET5, ASN74, PRO75, LEU76 have hydrophobic contacts with urea (b) with chain A of 2I1K, ASN6, GLU73 are forming hydrogen bonding and ASN74, MET5, LEU76 have hydrophobic contact with urea (c) with chain A of 2R2X, GLY121, VAL81 are forming hydrogen bonding and ILE172, PHE93, TYR80 have hydrophobic contacts with urea. 